\title{
KARAKTERSITIK FISIKO-KIMIA DAN SENSORIK JUS EKSTRAK BUAH SALAK (Salacca edulis Reinw) VARIETAS BONGKOK
}

\section{PHYSICO-CHEMICAL CHARACTERISTIC AND SENSORY OF SNAKE FRUIT ECTRACT JUICE (Salacca edulis Reinw) VARIETIES BONGKOK}

\author{
Leni Herliani Afrianti*, Yusman Taufik \& Hafni Gustianova \\ *Program Studi Teknologi Pangan, Fakultas Teknik, Universitas Pasundan \\ J1. Dr. Setiabudi No 93, Bandung, 40153, Indonesia \\ Alamat korespondensi: leni_priyatno@yahoo.com
}

\begin{abstract}
Abstrak: Salak merupakan salah satu tanaman buah tropis asli Indonesia. Salak varietas Bongkok berasal dari Kabupaten, Sumedang, Jawa Barat. Salak Bongkok mempunyai rasa yang asam, pahit dan sepet, oleh karena itu permintaan terhadap salak Bongkok ini rendah karena kurang diminati oleh konsumen. Buah salak Bongkok mengandung senyawa fenolik, alkaloid, flavonoid, saponin, tanin, terpenoid dan quinon. Tujuan dari penelitian untuk mengetahui karakteristik fisiko-kimia dan sensorik jus dari ekstrak buah salak (Salacca edulis Reinw.) varietas Bongkok. Metode penelitian menggunakan dua tahapan perlakuan. Untuk tahapan perlakuan pertama, membuat serbuk (simplisia) dari buah salak, ekstraksi simplisia dengan etanol 70\%, terakhir membuat jus buah dengan rasio antara ekstrak dan air, masing-masing (1:2); (1:3); (1:4); (1:5); (1:6), (1:7); (1:8); dan (1:9). Tahap perlakuan kedua adalah uji vitamin C, kadar alkohol, viskositas, dan uji sensorik dari jus buah salak. Rancangan percobaan yang digunakan pada penelitian ini adalah Rancangan Acak Kelompok (RAK) dengan 8 perlakuan dan ulangan sebanyak tiga kali untuk setiap kombinasi perlakuan sehingga diperoleh dua puluh empat percobaan. Rancangan analisis dibuat analisis variasi, selanjutnya untuk uji beda nyata menggunakan metode Duncan. Jus ekstrak buah salak Bongkok yang terpilih adalah jus dengan rasio antara ekstrak etanol dari buah dan air (1:4), dengan kadar Vitamin C adalah 3,38 mg/100 g; kadar alkohol 0,87\%; viskositas 0,0139 Cp; warna 3,57 ; aroma 4,0 dan rasa 4,22.
\end{abstract}

Kata kunci:Jus buah Salak var. Bongkok, Vitamin C, Viskositas, Kandungan alkohol, Uji sensorik

Abstract: Salak is one of the original tropical fruit plants from Indonesia. Salak Bongkok varieties, coming from Sumedang Regency West Java. Salak Bongkok has a sour, bitter taste and tart, therefore the demand for this low because the salak Bongkok are less sought after by consumers. Salak Bongkok fruit contain of phenolic compounds, alkaloids, flavonoids, saponins, tannins, terpenoids, and quinon. The aim of this study is to determine the physico-chemical characteristics and sensory of fruit juice extract of snake fruits (Salacca edulis Reinw.) varieties Bongkok. The method involved two treatment stages of research. The first treatment stage was to make powder (simplisia) of the fruits, to extract the simplisia with $70 \%$ ethanol, and then to make fruit juice with the ratio between the extract and water, (1:2); (1:3); (1:4); (1:5); (1:6), (1:7); (1:8); and(1:9), respectively. The second treatment stage was analyzed of vitamin $C$ and alcohol content, then analyzed of viscosity and sensory of the fruit juice. The experimental design using a randomized block design with 8 treatments and repeat each combination of treatment three times in order to obtain twenty four trials. The analysis model was made of variation analysis, subsequenty to test significant difference using Duncan method. Snake fruit juice chosen was juice with the ratio between the ethanol extract of the fruit and water (1:4), with vitamin C level of $3.38 \mathrm{mg} / 100 \mathrm{~g}$; alcohol content of 0.87\%; the viscosity of $0.0139 \mathrm{Cp}$; color was 3.57; smell was 4.0 and the taste was 4.22 .

Keywords: juice of snake fruit of var. Bongkok, vitamin C, viscosity, alcohol content, sensory test

\section{PENDAHULUAN}

Salak merupakan salah satu tanaman buah tropis asli Indonesia. Salak varietas Bongkok berasal dari Kabupaten, Sumedang, Jawa Barat. Salak Bongkok mempunyai rasa yang asam, pahit dan sepet, oleh karena itu permintaan terhadap salak Bongkok ini rendah karena kurang diminati oleh konsumen. Buah salak Bongkok mengandung senyawa fenolik, alkaloid, flavonoid, saponin, tanin, terpenoid dan quinon (Afrianti et al., 2007; Afrianti et al., 2010). Menurut Leong dan Shui (2002), rata-rata buah salak

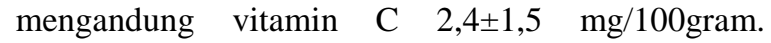
Sedangkan Vitamin C pada buah salak Bongkok adalah 8,37 mg/100 g berat bahan (Afrianti et al., 2006). Selain itu ekstrak etanol buah salak Bongkok mengandung antioksidan 2,45 $\pm 1,6 \mu \mathrm{g} / \mathrm{mL}$ (Afrianti et al., 2007) menjadikan buah salak layak untuk dibuat produk minuman yang menyehatkan. 
Salah satu diversifikasi produk minuman buah adalah membuat jus atau minuman sari buah.Jus buah dapat dibuat dari satu atau campuran berbagai jenis buah. Karena itu untuk meningkatkan nilai ekonomis buah salak Bongkok yang mempunyai potensi kesehatan bagi manusia maka perlu dilakukan diversifikasi buah dengan membuat jus buah dengan berbagai variasi rasio antara ekstrak dan air.

Keputusan Kepala Badan Pengawas Obat dan Makanan Nomor HK. No.HK.00.05.52.4040 Tahun 2006 tentang Kategori Pangan mengatur definisi dan karakteristik dasar sari buah, terkait ketentuan bahan baku, proses pengolahan dan produk jadi. Definisi sari buah adalah cairan yang diperoleh dari bagian buah yang dapat dimakan yang dicuci, dihancurkan, dijernihkan (jika dibutuhkan), dengan atau tanpa pasteurisasi dan dikemas untuk dapat dikonsumsi langsung.Sari buah dapat berisi hancuran buah, keruh, atau jernih. Pada sari buah hanya dapat ditambahkan konsentrat jika berasal dari jenis buah yang sama.

Anggraini (2010) membagi jus buah menjadi dua, yaitu sari buah yang dihasilkan langsung dari proses pengempaan, penghancuran dan penggilingan buah dan sari buah yang dihasilkan dari konsentrat dengan merekonstitusi konsentrat sari buah dengan air minum.Proses pembuatan sari buah harus dapat mempertahankan sifat fisik, kimia, dan organoleptik dan karakter zat gizi dari sari buah aslinya

Jumlah air yang ditambahkan pada jus buah tergantung pada jenis buah yang digunakan dan kepekatan sari buah yang diinginkan. Umumnya pengenceran yang digunakan untuk jus buah adalah sebanyak tiga sampai dengan empat kali volume sari buah, sedangkan pada jus lidah buaya adalah 1:2 (Fachruddin, 2011). Menurut Herawati dkk (2011) perbandingan konsentrat jus buah labu jepang dengan air yang paling disukai adalah 1:4.

\section{BAHAN DAN METODE}

Penelitian ini terbagi dalam dua tahap. Tahap pertama, pembuatan serbuk simplisia dilanjutkan dengan ekstraksi simplisia dengan etanol 70\%. Tahap kedua dilakukan pengujian vitamin C (AOAC, 2006), kadar alkohol, viskositas dan uji sensorik jus buah salak Bongkok dari ekstrak etanol 70\% dari buah.

\section{Pembuatan Simplisia (serbuk)}

Buah salak dilakukan blansing dengan suhu (60$70^{\circ} \mathrm{C}, 5-7$ menit), pengupasan kulit, pemotongan dan pengeringan dengan tunnel dryer selama 24 jam x 3 hari pada suhu $\pm 40-50{ }^{\circ} \mathrm{C}$.

\section{Ekstraksi}

Simplisia buah diekstraksi secara maserasiperkolasi pada suhu kamar dengan pelarut etanol $70 \%$ selama $3 \times 24$ jam. Selanjutnya ekstrak etanol dievaporasi sampai kental.

\section{Jus Buah Ekstrak Etanol}

Membuat jus buah dari ekstrak etanol dengan perbandingan ekstrak dengan air matang masingmasing adalah (1:2), (1:3), (1:4), (1:5), (1:6), (1:7), (1:8), dan (1:9). Selanjutnya jus buah dipasteurisasi pada suhu $60-70^{\circ} \mathrm{C}$ selama 15 menit. Rancangan percobaan yang digunakan pada penelitian ini adalah Rancangan Acak Kelompok (RAK) dengan delapan perlakuan dan ulangan sebanyak tiga kali untuk setiap kombinasi perlakuan sehingga diperoleh duapuluh empat percobaan. Rancangan analisis dibuat analisis variasi (ANAVA), selanjutnya untuk uji beda nyata menggunakan metode Duncan.

\section{Pengujian Vitamin C (AOAC, 1990)}

Sebanyak $50 \mathrm{~mL}$ jus buah dimasukkan ke dalam labu ukur, ditambah $25 \mathrm{~mL}$ asam metafosfat $20 \%$ kemudian diencerkan dengan air suling sampai batas tera dan dikocok hingga homogen. Sebanyak $10 \mathrm{~mL}$ larutan diambil dan di tambahkan dengan $2,5 \mathrm{~mL}$ aseton dan dititrasi dengan 2,6-diklorofenol indofenol. Titrasi dihentikan sampai terlihat warna merah jambu.

Perhitungan :

Keterangan:

$$
\text { Konsentrasi sampel }=\frac{V 2-V o}{V 1-V o} \times C 1
$$

$\mathrm{V}_{1}=$ volume larutan 2,6-diklorofenol indofenol yang digunakan untuk titrasi standar vitamin $\mathrm{C}$

$\mathrm{V}_{2}=$ volume larutan 2,6-diklorofenol indofenol yang digunakan untuk titrasi larutan sampel

$\mathrm{Vo}=$ volume larutan 2,6-diklorofenol indofenol yang digunakan untuk titrasi larutan blanko

$\mathrm{C}_{1}=$ Konsentrasi larutan satndar vitamin $\mathrm{C}$ Kadar vitamin C sebagai mg/100 g sampel

\section{Uji Alkohol (SNI, 1995)}

Sari buah dipipet $50 \mathrm{~mL}$ dan dimasukkan ke dalam labu destilat. Sebanyak $50 \mathrm{~mL}$ aquadest dan batu didih ditambahkan dan kemudian didestilasi. Hasil destilasi \pm sebelum tanda batas dalam labu ukur $50 \mathrm{~mL}$. Destilasi dihentikan pada saat cairan destilat kurang lebih $1 \mathrm{~cm}$ dari garis batas destilat dan ditepatkan dengan aquades sampai tanda batas dan dihomogenkan, lalu ditutup rapat. Berat jenis alkoholnya dihitung dan dikonversikan ke tabel untuk menghitung kadar alkoholnya.

\section{Uji Viskositas (AOAC, 1990)}

Pengujian viskositas diawali dengan pengujian berat jenis sari buah dengan menggunakan piknometer. Piknometer kosong ditimbang (m) kemudian aquades $10 \mathrm{~mL}$ dimasukkan ke dalam piknometer, sampel dimasukkan ke dalam piknometer $10 \mathrm{~mL}$ ditimbang $\left(\mathrm{m}^{\prime}\right)$. Aquades $10 \mathrm{~mL}$ dimasukkan ke dalam pipa Ostwald dan dihisap sampai tanda merah tera bagian atas. Waktu turun aquades sampai tanda tera dihitung ( $\mathrm{t}$ air). Sampel 10 $\mathrm{mL}$ dimasukkan ke dalam pipa Ostwald dan dihisap sampai tera bagian atas. Waktu turun sampel sampai 
tanda tera dihitung (t sampel). Kekentalan viskositas dihitung :

$$
\begin{aligned}
& \text { Viskositas }=\frac{\rho \text { sampel } \mathrm{xt} \text { sampel } \mathrm{x} \text { nair }}{\rho \text { air } \mathrm{x} \mathrm{tair}} \\
& \text { psampel }=\frac{\mathrm{m}^{\prime}-\mathrm{m}}{v}
\end{aligned}
$$

\section{Keterangan:}

$\begin{array}{lll}\mathrm{m} & : & \text { massa piknometer kosong }(\mathrm{g}) \\ \mathrm{m}^{\prime} & : & \text { massa piknometer kosong }+ \text { sampel }(\mathrm{g}) \\ \mathrm{v} & : & \text { volume piknometer }(\mathrm{mL}) \\ \mathrm{\eta} & : & \text { viskositas air }(1,0 \mathrm{Cp}) \\ \mathrm{P} & : & \text { berat jenis sampel }(\mathrm{g} / \mathrm{ml}) \\ \mathrm{t} \text { sampel } & : & \text { waktu alir sampel }(\text { detik }) \\ \mathrm{t} \text { air } & : & \text { waktu alir air (detik) }\end{array}$

\section{Uji Organoleptik}

Pengujian dilakukan menggunakan uji hedonik (kesukaan) oleh lima belas orang panelis agak terlatih berusia 18-21 tahun. Panelis dipilih dari mahasiswa Prodi Teknologi Pangan Universitas Pasundan yang sudah mendapatkan mata kuliah praktikum uji inderawi. Penilaian kesukaan dilakukan dengan cara sampel yang telah disediakan dicicipi dan diberikan penilaian terhadap tingkat kesukaan. Skor yang diberikan adalah 1-5, mulai dengan sangat tidak suka (skor 1), tidak suka (skor 2), agak suka (skor 3), suka (skor 4) dan sangat suka (skor 5).

\section{HASIL DANPEMBAHASAN \\ Kadar Vitamin C}

Berdasarkan hasil analisis variasi, menunjukkan bahwa rasio ekstrak etanol dengan air berpengaruh nyata terhadap kadar vitamin $\mathrm{C}$ jus buah salak Bongkok $(p \geq 0,05)$.

Tabel 1. Kadar vitamin C jus buah salak Bongkok.

\begin{tabular}{cc}
\hline $\begin{array}{c}\text { Perbandingan Ekstrak } \\
\text { (Etanol : Air) }\end{array}$ & $\begin{array}{c}\text { Vitamin C } \\
(\mathbf{m g} / \mathbf{1 0 0} \mathbf{g})\end{array}$ \\
\hline $1: 9$ & $0,67 \pm 0,01 \mathrm{a}$ \\
$1: 8$ & $1,35 \pm 0,012 \mathrm{~b}$ \\
$1: 7$ & $1,50 \pm 0,01 \mathrm{~b}$ \\
$1: 6$ & $2,20 \pm 0,02 \mathrm{c}$ \\
$1: 5$ & $2,90 \pm 0,013 \mathrm{c}$ \\
$1: 4$ & $3,38 \pm 0,02 \mathrm{~d}$ \\
$1: 3$ & $4,50 \pm 0,02 \mathrm{e}$ \\
$1: 2$ & $4,73 \pm 0,011 \mathrm{e}$ \\
\hline
\end{tabular}

Semakin tinggi konsentrasi ekstrak yang ditambahkan (1:2) maka kadar vitamin C semakin tinggi yaitu 4,73 $\mathrm{mg} / 100 \mathrm{~g}$, sedangkan vitamin $\mathrm{C}$ terendah terdapat pada (1:9) dengan Vitamin $C$ sebesar $0,67 \pm 0,01 \mathrm{mg} / 100 \mathrm{~g}$. Selain mudah rusak, vitamin $\mathrm{C}$ juga mudah larut dalam air. Kadar vitamin C buah simplisia salak Bongkok adalah $8,37 \mathrm{mg} / 100$ g (Afrianti et al., 2007), namun setelah menjadi minuman jus buah terjadi penurunan secara signifikan, hal ini karena terjadi proses pemanasan pada suhu $60-70^{\circ} \mathrm{C}$ selama 15 menit.

\section{Kadar Alkohol}

Berdasarkan hasil analisis variasi, menunjukkan bahwa perbandingan ekstrak dengan air berpengaruh nyata terhadap kadar alkohol jus buah salak Bongkok ( $\mathrm{p} \geq 0,05)$. Rasio ekstrak dengan air terhadap kadar alkohol jus buah ditunjukkan pada Tabel 2 .

Rasio ekstrak dengan air (1:2) mempunyai kadar alkohol 1,16\%, sedangkan rasio (1:9) adalah 0,31\%. Adanya kandungan alkohol pada jus buah salak, karena pelarut yang digunakan saat ekstraksi adalah etanol 70\%, dan evaporasi (penguapan) tidak optimal untuk menguapkan etanol, sehingga jus buah masih mengandung alkohol.

Menurut konsep standar perdagangan tahun 1975 dalam Siswadji (1985) bahwa minuman ringan dapat didefinisikan sebagai minuman yang dibuat untuk dapat diminum langsung tanpa diencerkan atau setelah diencerkan, dan dapat berupa minuman ringan yang tidak mengandung etanol dan minuman ringan yang mengandung etanol dengan kadar tidak lebih dari $1,5 \%$ yang dapat berupa hasil fermentasi atau campuran minuman ringan dan minuman keras.

Namun menurut SNI 01-3719-1995, minuman sari buah atau jus adalah minuman ringan yang dibuat dari sari buah dan air dengan atau tanpa penambahan gula dan bahan tambahan makanan yang diizinkan, tidak difermentasi dan tidak mengandung alkohol.

Tabel 2. Kadar alkohol jus buah salak.

\begin{tabular}{cl}
\hline $\begin{array}{c}\text { Perbandingan Ekstrak } \\
\text { (Etanol : Air })\end{array}$ & $\begin{array}{c}\text { Kadar Alkohol } \\
(\boldsymbol{\%})\end{array}$ \\
\hline $1: 9$ & $0,29 \pm 0,020 \mathrm{a}$ \\
$1: 8$ & $0,31 \pm 0,010 \mathrm{a}$ \\
$1: 7$ & $0,60 \pm 0,010 \mathrm{~b}$ \\
$1: 6$ & $0,65 \pm 0,013 \mathrm{~b}$ \\
$1: 5$ & $0,69 \pm 0,022 \mathrm{~b}$ \\
$1: 4$ & $0,87 \pm 0,012 \mathrm{c}$ \\
$1: 3$ & $0,96 \pm 0,010 \mathrm{c}$ \\
$1: 2$ & $1,16 \pm 0,010 \mathrm{~d}$ \\
\hline
\end{tabular}

\section{Viskositas}

Viskositas merupakan ukuran kekentalan fluida yang menyatakan besar kecilnya gesekan di dalam fluida. Makin besar viskositas suatu fluida, maka makin sulit suatu fluida mengalir dan makin sulit suatu benda bergerak di dalam fluida tersebut. Di dalam zat cair, viskositas dihasilkan oleh gaya kohesi antara molekul zat cair.

Berdasarkan hasil analisis variasi, rasio ekstrak salak dan air berpengaruh nyata terhadap viskositasjus buah salak Bongkok ( $\mathrm{p} \geq 0,05)$. Viskositas jus buah salak ditunjukkan pada Tabel 3. Berdasarkan uji lanjut Duncan terdapat perbedaan yang nyata terhadap viskositas. Viskositas terbesar pada rasio 1:2 yaitu $0,0207 \mathrm{Cp}$, sedangkan viskositas terkecil adalah 0,0105 $\mathrm{Cp}$ dengan rasio $1: 9$. 
Viskositas adalah sifat fisika yang dapat dilakukan dalam pengujian bahan pangan salah satunya adalah jus buah salak, dimana semakin besar nilai viskositas jus buah maka menunjukkan semakin kental konsentrasi bahan tersebut. Perubahan ini terjadi karena semakin banyak jumlah air yang ditambahkan terhadap ekstrak maka viskositas produk akan semakin kecil dan begitupun sebaliknya, semakin sedikit air yang ditambahkan terhadap ekstrak maka viskositasnya pun akan semakin tinggi.

Tabel 3. Viskositas jus buah salak Bongkok.

\begin{tabular}{cc}
\hline $\begin{array}{c}\text { Perbandingan Ekstrak } \\
\text { etanol : Air }\end{array}$ & Viskositas (Cp) \\
\hline $1: 9$ & $0,0105 \pm 0,010 \mathrm{a}$ \\
$1: 8$ & $0,0110 \pm 0,010 \mathrm{~b}$ \\
$1: 7$ & $0,0111 \pm 0,012 \mathrm{c}$ \\
$1: 6$ & $0,0126 \pm 0,020 \mathrm{~d}$ \\
$1: 5$ & $0,0136 \pm 0,020 \mathrm{e}$ \\
$1: 4$ & $0,0139 \pm 0,021 \mathrm{e}$ \\
$1: 3$ & $0,0147 \pm 0,022 \mathrm{f}$ \\
$1: 2$ & $0,0207 \pm 0,020 \mathrm{~g}$ \\
\hline
\end{tabular}

Menurut Brennan (1974), ketika suatu cairan melalui suatu tabung, lapisan zat cair yang bersentuhan langsung dengan dinding tabung relatif diam, sementara cairan di tengah relatif mengalir dengan kecepatan yang tinggi. Besarnya gaya gesekan yang terjadi antara zat yang bergerak dengan yang diam inilah dinamakan koefisien viskositas atau sering juga hanya disebut viskositas. Semakin kuat interaksi partikel cairan yang bergerak akan semakin besar viskositasnya, dengan kata lain zat cair itu semakin kental.

\section{Uji Organoleptik}

Uji organoleptik pada jus buah salak Bongkok adalah atribut warna, aroma, dan rasa.

\section{Warna}

Penentuan mutu bahan pangan sebelum faktor lain dijadikan bahan pertimbangan faktor warna tampil lebih dahulu, kadang-kadang sangat menentukan, suatu bahan pangan yang bernilai gizi, enak dan teksturnya sangat baik, kurang diminati bila memiliki warna yang tidak sedap dipandang atau memberi kesan telah menyimpang dari warna yang seharusnya (Winarno, 1997).

Berdasarkan hasil uji organoleptik terhadap atribut warna jus buah salak Bongkok menunjukkan adanya pengaruh yang sangat nyata $(\mathrm{p} \geq 0,05)$. Warna jus buah salak Bongkok ditunjukkan pada Tabel 4 . Warna yang paling disukai oleh panelis yaitu rasio ekstrak dan air (1:9) dengan rata-rata sebesar 4,72. Sedangkan warna yang kurang disukai oleh panelis yaitu rasio ekstrak dengan air (1:2) dengan rata-rata sebesar 2,17.

Sebagian bahan pangan mengalami perubahan warna seperti karamelisasi karena proses, pemanasan menyebabkan produk berwarna kecoklatan, proses pencoklatan terjadi oleh enzim fenolase yang bereaksi dengan gula. Pencoklatan juga disebabkan kontak langsung dengan udara luar secara oksidatif, atau logam. Inaktivasi enzim fenolase adalah dengan proses blanching, buah salak dilakukan pemanasan dengan suhu sekitar $60^{\circ} \mathrm{C}$ selama kurang dari 10 menit.

Tabel 4. Warna jus buah salak Bongkok.

\begin{tabular}{cc}
\hline $\begin{array}{c}\text { Perbandingan Ekstrak } \\
\text { (Etanol : Air) }\end{array}$ & Warna \\
\hline $1: 2$ & $2,17 \pm 0,5 \mathrm{a}$ \\
$1: 3$ & $2,93 \pm 0,7 \mathrm{~b}$ \\
$1: 4$ & $3,57 \pm 0,25 \mathrm{c}$ \\
$1: 5$ & $3,70 \pm 0,6 \mathrm{~d}$ \\
$1: 6$ & $3,75 \pm 0,9 \mathrm{~d}$ \\
$1: 7$ & $3,87 \pm 0,56 \mathrm{e}$ \\
$1: 8$ & $4,30 \pm 0,23 \mathrm{e}$ \\
$1: 9$ & $4,72 \pm 0,45 \mathrm{f}$ \\
\hline
\end{tabular}

Penambahan air pada jus buah salak mempengaruhi tingkat kesukaan panelis, ini ditunjukkan pada Tabel 4, perbandingan ekstrak dan air (1:9) mempunyai nilai rata-rata lebih disukai oleh panelis. Panelis lebih menyukai warna kuning dan bening, dibandingkan dengan warna jus buah yang pekat.

\section{Aroma}

Berdasarkan hasil uji organoleptik terhadap atribut aroma jus buah salak menunjukkan bahwa perbandingan ekstrak dengan air memberikan pengaruh nyata terhadap aroma jus buah salak Bongkok $(\mathrm{p} \geq 0,05)$. Pengaruh perlakuan perbandingan ekstrak dan air pada jus buah salak Bongkok ditunjukkan pada Tabel 5.

Tabel 5. Aroma jus buah salak Bongkok.

\begin{tabular}{cc}
\hline $\begin{array}{c}\text { Perbandingan Ekstrak } \\
\text { (Etanol : Air) }\end{array}$ & Aroma \\
\hline $\mathrm{a}_{1}(1: 2)$ & $3,12 \pm 0,1$ \\
$\mathrm{a}_{2}(1: 3)$ & $3,55 \pm 0,1$ \\
$\mathrm{a}_{7}(1: 8)$ & $3,70 \pm 0,5$ \\
$\mathrm{a}_{4}(1: 5)$ & $3,92 \pm 0,4$ \\
$\mathrm{a}_{3}(1: 4)$ & $4,00 \pm 0,2$ \\
$\mathrm{a}_{6}(1: 7)$ & $4,05 \pm 0,1$ \\
$\mathrm{a}_{8}(1: 9)$ & $4,08 \pm 0,5$ \\
$\mathrm{a}_{5}(1: 6)$ & $4,13 \pm 0,3$ \\
\hline
\end{tabular}

Aroma yang paling disukai oleh panelis yaitu dengan rasio ekstrak dan salak yaitu 1:6 dengan ratarata 4,13 , sedangkan aroma pada 1:2 mempunyai nilai rata-rata 3,12 masih pada level disukai panelis.

\section{Rasa}

Rasa merupakan faktor yang juga cukup penting dari suatu produk minuman. Komponen yang dapat menimbulkan rasa yang diinginkan tergantung dari senyawa penyusunnya. Umumnya bahan pangan tidak hanya terdiri dari satu rasa saja akan tetapi gabungan dari berbagai macam rasa yang terpadu sehingga menimbulkan citarasa yang utuh. Faktor 
dan konsistensi suatu bahan pangan mempengaruhi citarasa yang ditimbulkan oleh bahan tersebut. Perubahan yang terjadi pada citarasa bahan pangan biasanya lebih kompleks daripada yang terjadi pada warna bahan pangan (Winarno, 1997).

Rasa yang ditimbulkan oleh bahan pangan berasal dari sifat bahan itu sendiri atau pada saat proses ditambahkan dengan zat lain sehingga rasa aslinya bisa berkurang ataupun bertambah. Selain itu rasa yang terdapat pada produk makanan dapat berubah dari rasa yang sebenarnya atau yang diharapkan, hal ini tergantung dari senyawa penyusunnya, misalnya gula yang dapat memberikan rasa manis pada beberapa produk makanan (Kartika dkk, 1988).

Berdasarkan hasil uji sensorik atribut rasa jus buah salak Bongkok menunjukkan tingkat kesukaan panelis pada rasio dari ekstrak dan air berpengaruh nyata terhadap rasa jus buah salak $(\mathrm{p} \geq 0,05)$. Rasa jus buah salak Bongkok ditunjukkan pada Tabel 6 .

Atribut rasa yang paling disukai oleh panelis adalah rasio ekstrak dan air (1:4) dan rata-rata yang diperoleh sebesar 4,22, sedangkan rasa yang kurang disukai oleh panelis adalah (1:8) dan rata-rata yang diperoleh sebesar 2,70. Rasio 1:4 merupakan rasio yang tepat unruk atribut rasa karena penambahan tidak terlalu banyak dan juga tidak sedikit sehingga rasa dari jus buah mempunyai keasaman yang cukup. Penambahan air yang terlalu banyak dengan rasio dari 1:5 sampai 1:9 mempunyai rasa tidak disukai karena jus berasa hambar, sedangkan penambahan air yang terlalu sedikit yaitu 1:2 dan 1:3 menjadikan rasa jus sangat asam.

Tabel 6. Rasa jus buah salak Bongkok.

\begin{tabular}{cc}
\hline $\begin{array}{c}\text { Perbandingan Ekstrak } \\
\text { etanol : Air }\end{array}$ & Rasa \\
\hline $\mathrm{a}_{7}(1: 8)$ & $2,70 \pm 0,1$ \\
$\mathrm{a}_{8}(1: 9)$ & $3,10 \pm 0,1$ \\
$\mathrm{a}_{6}(1: 7)$ & $3,32 \pm 0,5$ \\
$\mathrm{a}_{5}(1: 6)$ & $3,38 \pm 0,4$ \\
$\mathrm{a}_{1}(1: 2)$ & $3,65 \pm 0,2$ \\
$\mathrm{a}_{4}(1: 5)$ & $3,95 \pm 0,1$ \\
$\mathrm{a}_{2}(1: 3)$ & $4,12 \pm 0,5$ \\
$\mathrm{a}_{3}(1: 4)$ & $4,22 \pm 0,3$ \\
\hline
\end{tabular}

\section{KESIMPULAN}

Jus ekstrak buah salak Bongkok yang terpilih adalah rasio antara ekstrak etanol $70 \%$ dari buah dan air (1:4), dengan kadar Vitamin $\mathrm{C}$ adalah 3,38 $\mathrm{mg} / 100 \mathrm{~g}$; viskositas $0,0139 \mathrm{Cp}$; warna 3,57 ; aroma 4,0 dan rasa 4,22. Jus buah salak Bongkok belum sesuai dengan syarat SNI 01-3719-1995, karena masih mengandung alkohol $0,87 \%$.

\section{UCAPAN TERIMA KASIH}

Kami ucapkan terimakasih kepada Hibah Kompetensi DP2M yang telah memberikan dana penelitian tahun anggaran 2014.

\section{DAFTAR PUSTAKA}

Afrianti, L.H, Slamet, I., Adnyana, I.K., \& Elin, Y.S, (2006), Aktivitas Antioksidan Ekstrak Daging Buah Salak Varietas Bongkok (Salacca edulis Reinw), Acta Pharmaceutica Indonesia.

Afrianti, L.H, Slamet, I., Adnyana, I.K. \&Elin Y.S. (2007). Xanthine Oxidase inhibitor activity of terpenoid and pyrrolecompounds isolated from snake fruit (Salacca edulis Reinw) variety of Bongkok. J. Applied Sciences,7(20): 3127-3130.

Anggraini, I. (2010). Klasifikasi dan Pelabelan Minuman Buah.www.foodreview.biz.

Brennan. J. G. (1974). Food Engineering Operations, Applied Science Publisher Limited. London

Fachruddin, L. (2011).Membuat Aneka Sari Buah, Penerbit Kanisius, Yogjakarta.

Herawati.(2011).Pengolahan Konsentrat Sari Buah Labu Jepang (Kobucha) dengan Menggunakan Evaporator Vakum, Balai Pengkajian Teknologi Pertanian Jabar, Fakultas Teknologi Pertanian IPB, Bogor.

Kartika, B., Hastuti, P., dan Supartono, W. (1988).Pedoman Uji Inderawi Bahan Pangan, Universitas Gadjah Mada, Yogyakarta

Siswadji, C.L. (1985). Pembuatan Minuman Sari Tape Dari Ekstraksi Tape Ubi Kayu, Institut Pertanian Bogor, Bogor

Standar Nasional Indonesia 01-3719, (1995), Minuman Sari Buah, Dewan Standarisasi Nasional.

Winarno, F, G., (1997), Kimia Pangan dan Gizi, Penerbit PT.Gramedia Pustaka Utama, Jakarta. 